\title{
PERCEPÇÃO AMBIENTAL DA POPULAÇÃO URBANA PRÓXIMA AO RIO BURITI NO MUNICÍPIO DE SÃO BERNARDO/MA
}

\author{
Enio Oliveira Ferreira de Sousa ${ }^{1}$ \\ Natilene Mesquita Brito ${ }^{2}$ \\ Ozelito Possidônio de Amarante Junior ${ }^{3}$
}

Resumo: A percepção ambiental tem sido empregada como base para projetos de Educação Ambiental, pois identifica relações existentes entre seres humanos e ambiente. Reconhecer essas relações é importante para descobrir as causas de impactos ambientais. O município de São Bernardo/MA, sofre vários impactos ambientais, principalmente sobre o Rio Buriti, que banha esse município e é considerado um recurso hídrico importante. Este trabalho de percepção ambiental identificou as relações entre a comunidade e o rio, gerando resultados que poderão embasar futuras pesquisas. O objetivo deste trabalho foi avaliar a percepção ambiental da população que vive mais próxima ao rio. Para isso, foi aplicado um questionários a 199 moradores. Os resultados sugeriram uma percepção ambiental mais adequada dos participantes do que o esperado, pois muitos apontaram causas e soluções coerentes para a problemática ambiental.

Palavras-chave: Percepção ambiental. Aspectos socioambientais. Ribeirinhos.

\section{ENVIRONMENTAL PERCEPTION OF URBAN POPULATION NEXT TO RIO BURITI IN SÃO BERNARDO/MA}

Abstract: Environmental perception has been employed as a basis for projects on environmental education, as it identifies relationships between humans and the environment. Acknowledging these relationships is important to discover the causes of environmental impacts. The town of São Bernardo, MA, suffers from various environmental impacts, especially on the Buriti River, which flows past this town and is considered an important hydric resource. This study of environmental perception would identify the relationships between the community and the river, generating results that could be configured as a basis for future research. The purpose of this study was to evaluate the environmental perception of the population who lives near the river. Thus, a questionnairy was given to 119 respondents. The results suggested that participants' environmental

\footnotetext{
${ }^{1}$ Biólogo. Mestre em Biodiversidade e Conservação pela Universidade Federal do Maranhão. enio-oliveira@bol.com.br

${ }^{2}$ Doutora em Química Analítica pela Universidade de São Paulo.. Professora Associada, Departamento de Química e Alimentos. Campus São Luís - Monte Castelo. Instituto Federal de Educação, Ciência e Tecnologia do Maranhão. natilene@ifma.edu.br

${ }^{3}$ Químico Industrial. Mestre em Química Analítica. Doutor em Ciências da Engenharia Ambiental. Professor Associado, Departamento de Química e Alimentos. Campus São Luís Monte Castelo. Instituto Federal de Educação, Ciência e Tecnologia do Maranhão. ozelito@ifma.edu.br
} 
perception is more adequate than expected, as many of them pointed causes and coherent solutions to environmental problems.

Keywords: Environmental perception. Socio-environmental aspects. Riparian.

\section{PERCEPCIÓN AMBIENTAL DE POBLACIÓN URBANA JUNTO AL RÍO BURITI EN SÃO BERNARDO/MA}

Resumen: La percepción ambiental se ha utilizado como base para proyectos de educación ambiental, pués identifica las relaciones entre los seres humanos y el medio ambiente. Reconocer estas relaciones es importante para descubrir las causas de los impactos ambientales. La ciudad de São Bernardo/MA, sufre una serie de impactos ambientales, sobre todo en el Río Buriti, que baña este municipio y se considera un importante recurso de agua. Este estudio identificó la percepción de las relaciones ambientales entre la comunidad y el río, lo que generó resultados que pueden apoyar la investigación futura. El objetivo de este estudio fue evaluar la percepción ambiental de la población que vive más cercana al río. Para ello, un cuestionario fue administrado a 199 residentes. Los resultados sugieren una percepción ambiental más adecuado de los participantes de las esperadas, ya que muchos han señalado las causas y soluciones coherentes a los problemas ambientales.

Palabras clave: Percepción ambiental. Aspectos sociales y ambientales. Ribereños.

\section{Introdução}

Conforme Faggionato (2009), a percepção ambiental é definida como a tomada de consciência do ambiente no qual está inserido o ser humano. Essa percepção está diretamente relacionada com as múltiplas relações que envolvem o ser humano e o ambiente. De acordo com Okamoto (2003) a percepção ambiental do ser humano é produto dos componentes sensorial (reação dos sentidos) e racional (inteligência de cada indivíduo), assegurados através da ética ambiental, que é o respeito ao meio ambiente.

Trabalhos de percepção ambiental são utilizados por muitos autores como o primeiro passo para pesquisas no campo da EA, já que é necessário conhecer a realidade, os costumes e a cultura local, ou seja, os aspectos sociais, para depois propor intervenções. Marques, Carniello e Neto (2010) afirmam que metodologias de EA podem ser propostas ou analisadas, utilizando-se estudos sobre percepção do ambiente.

No município de São Bernardo nunca houve um trabalho de percepção ambiental focado na população, relativo ao Rio Buriti que banha a cidade, mesmo sendo muito utilizado pela população local para banho, pesca, consumo e lavagem de roupas e louças, revelando seu grau de importância, estando sujeito a muitos impactos ambientais. A cidade como um todo sofre sérios problemas ambientais, como a presença de esgoto escoando a céu aberto, como exemplo da falta de saneamento básico, lixo nas ruas, desmatamento, queimadas e assoreamento, entre outros. Associada a isso, a falta de uma gestão ambiental por parte do poder público, uma vez que, atualmente, o município não conta com uma Secretaria Municipal de Meio Ambiente. Esses dados apontam para a importância e a necessidade de um trabalho para identificar 
a percepção ambiental da população, podendo servir como base para trabalhos de Educação Ambiental, tanto para pesquisadores, como para o poder público e para escolas. Diante disso, o objetivo deste trabalho foi avaliar a percepção ambiental da população que vive mais próxima ao Rio Buriti.

\section{Material e Métodos}

\subsection{Caracterização da área}

O município de São Bernardo localiza-se na microrregião Leste Maranhense, na região do Baixo Parnaíba Maranhense. Apresenta clima tropical quente e semiárido da zona equatorial, e a vegetação caracteriza-se pela presença de cerrado e mata de transição entre esse bioma e a floresta Amazônica, situada a oeste do Estado. Sua área é de $1.007 \mathrm{~km}^{2}$. Possui 7.152 domicílios com 26.476 habitantes, sendo cerca de $44 \%$ na zona urbana e $56 \%$ na zona rural (IBGE, 2014).

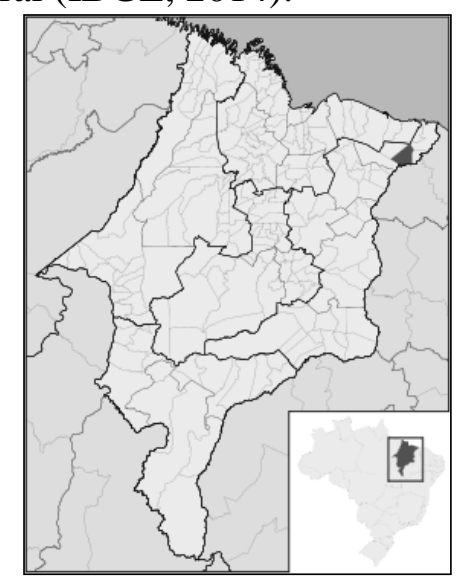

Figura 1 - Localização do município de São Bernardo/MA. Fonte: Wikipédia, 2010.

\subsection{Metodologia}

Segundo Faggionato (2009), existem várias formas de se estudar a percepção ambiental, entre elas o uso de questionários, mapas mentais e até representação fotográfica. Para a autora, existem trabalhos de percepção ambiental que buscam não apenas o entendimento do que o indivíduo percebe, mas promover a sensibilização, bem como o desenvolvimento do sistema de percepção e compreensão do ambiente.

Foi aplicado um questionário aos moradores de casas das ruas que ficam mais próximas ao Rio Buriti, na zona urbana do Município. A amostra foi baseada na quantidade de domicílios presentes nas ruas. A aplicação dos questionários ocorreu no período diurno. Utilizou-se, como critério de inclusão na pesquisa, o fato de os domicílios se localizarem nas seguintes ruas: da Caema, Bernardo Lima, Barão do Rio Branco, Domingos Freitas Diniz, São Felipe, Edmundo Pereira, além da travessa Alexandre Mendes e da Avenida Vitorino Freire. O critério de exclusão foi a declaração expressa do indivíduo presente no domicílio em não querer participar da pesquisa. Não houve critérios para a idade do participante. Utilizando a aplicação dos questionários, foi realizado levantamento de dados com o intuito de identificar os principais aspectos socioambientais, além da percepção ambiental da comunidade, entendendo-se, esta última, como a forma de cada ator social compreender e relatar sua relação com o 
ambiente em que está inserido. A presente pesquisa foi aprovada pelo Comitê de Ética na Pesquisa da UFMA (Número do protocolo: 23115-011024/2009-36).

\section{Resultados e Discussão}

Foram aplicados 119 questionários. Cada entrevista durou cerca de 30 minutos. Foram visitados mais de 150 domicílios, sendo que alguns não possuíam moradores no momento da visita. Dos domicílios visitados, 31 pessoas se recusaram a participar da pesquisa pelos mais diversos motivos, dentre eles: desconfiança por ter que assinar o Termo de Consentimento Livre e Esclarecido; acreditar que a pesquisa era de cunho político; receio de não saber responder; falta de vontade em participar; ou simplesmente por desconhecimento do tema.

De acordo com os dados dos questionários, o gênero feminino $(66,4 \%)$ foi o que prevaleceu entre os participantes. Uma possível explicação para essa relação é o fato de que, em cidades do interior, ainda há um grande número de lares em que o homem sai para trabalhar e a mulher permanece como a dona de casa. Observou-se que esse fato é mais evidente no período matutino, uma vez que é o horário em que os maridos estão desenvolvendo suas atividades econômicas fora de casa. Os resultados se assemelham ao de Martins e Lopes (2009) ao pesquisarem a percepção ambiental de ribeirinhos no estuário do Rio Anil, em São Luís/MA. Nesse estudo 74\% eram do sexo feminino e $26 \%$ do sexo masculino.

Com relação ao grau de escolaridade, a maioria possuía ensino fundamental incompleto e ensino médio completo, com $33,6 \%$ e $31,9 \%$, respectivamente. Dado muito semelhante foi coletado no estudo de Martins e Lopes (2009), em que a maioria (32\%) também possuía o ensino fundamental incompleto. Lima (2003) também encontrou um maior número de entrevistados com ensino fundamental incompleto (35\%) ao trabalhar com moradores da cidade de São Carlos/SP, no entorno da bacia hidrográfica do Rio Monjolinho. Caldas e Rodrigues (2005) encontraram o maior percentual dos entrevistados com ensino fundamental incompleto, ao trabalhar com a comunidade ribeirinha da microbacia do Rio Magu, localizado na parte rural oeste do Estado do Maranhão.

Com relação à idade, o maior número de participantes possuía entre 16 e 30 anos (33,6\%), seguida da idade entre 31 e 45 anos (26,0\%). Na faixa etária de 16 a 30 anos verificou-se que algumas pessoas declararam possuir vontade de mudar a realidade, almejando um futuro melhor para si. Mais uma vez, os dados de Martins e Lopes (2009) são semelhantes, ou seja, a maioria (31\%) possuía entre 31 e 40 anos. Isto pode ser um indicativo que o público a ser trabalhado em atividades de Educação Ambiental nessa comunidade ribeirinha está composto por jovens e adultos.

Quando se analisa o grau de escolaridade e a idade dos participantes, observa-se uma discrepância entre as porcentagens das pessoas que possuem ensino fundamental incompleto $(33,6 \%)$ e idade de 0 a 15 anos $(10,1 \%)$, ou seja, isso indica que uma parcela da comunidade com idade superior àquela esperada para concluir o Ensino Fundamental não concluiu esse nível de ensino, apontando uma distorção idade/grau de escolaridade, o que pode indicar deficiência do ensino, podendo ser causada por motivos pessoais ou de políticas públicas.

Em relação aos domicílios, 92,4\% dos domicílios possuem fossa do tipo cisterna coletora para o recebimento de esgoto sanitário ou fossa seca. A Figura 2 traz um gráfico que permite observar o destino do esgoto das casas. 


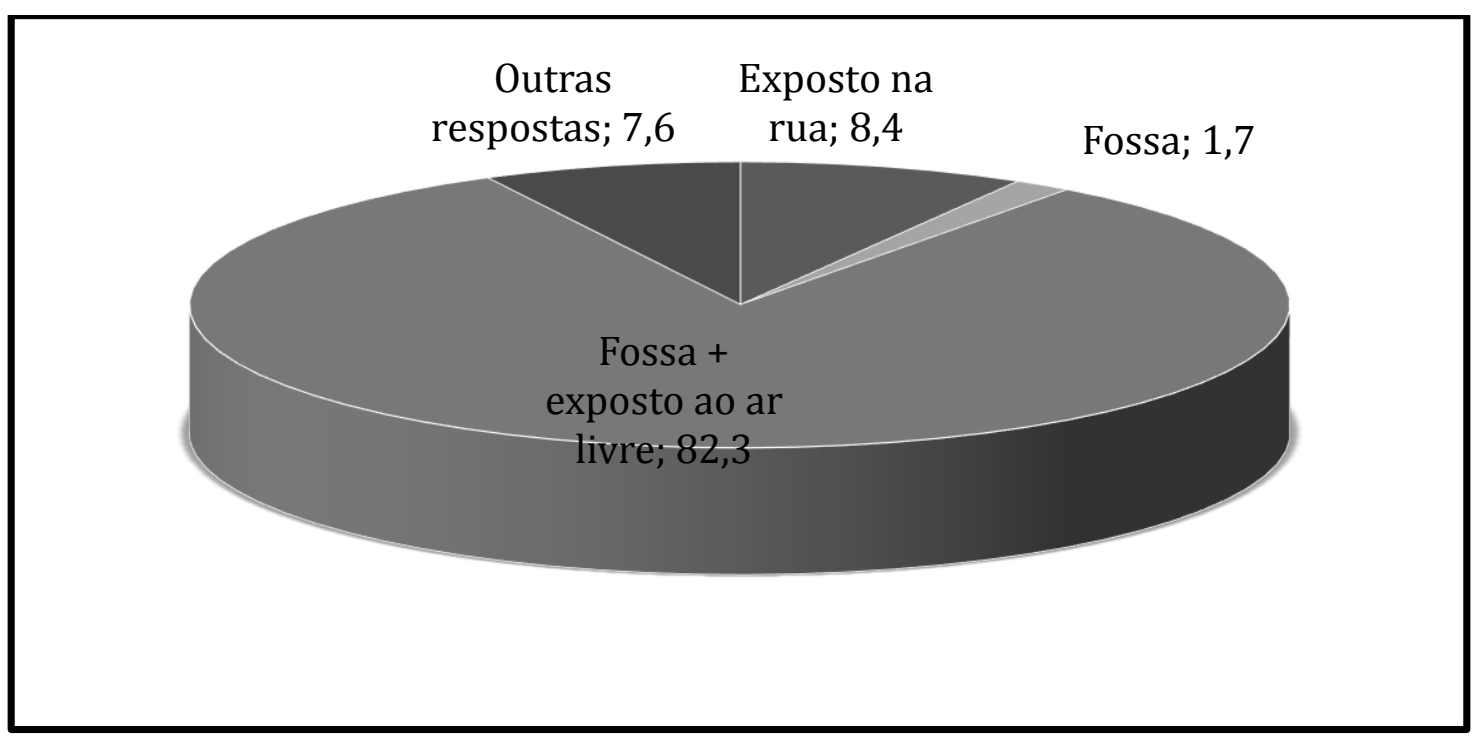

Figura 2 - Gráfico sobre o destino do esgoto das casas.

De acordo com a Figura 2, em 82,3\% das casas o esgoto doméstico vai para a fossa. As águas servidas de pia, tanque de lavar roupas e chuveiros, ficam expostas ao ar livre, sendo esta disposição, na maioria dos casos, feita na rua, cabendo ressaltar que as ruas pesquisadas estão localizadas próximas do Rio Buriti. Esse fato pode indicar uma poluição do rio por efluentes domésticos e grande deficiência local de infraestrutura de saneamento básico. Como outras respostas $(7,6 \%)$, a maioria relatou que o destino do esgoto é o quintal da casa, sendo que há casas literalmente na margem do rio, como pode ser observado na Figura 3. Na pesquisa de Bergmann (2007) houve dois fatos semelhantes: (i) o esgotamento sanitário da população era feito através de fossa ou sumidouro, e (ii) em alguns casos não há encanamento adequado para o destino da água servida, sendo que esta acumula-se em fossas a céu aberto.

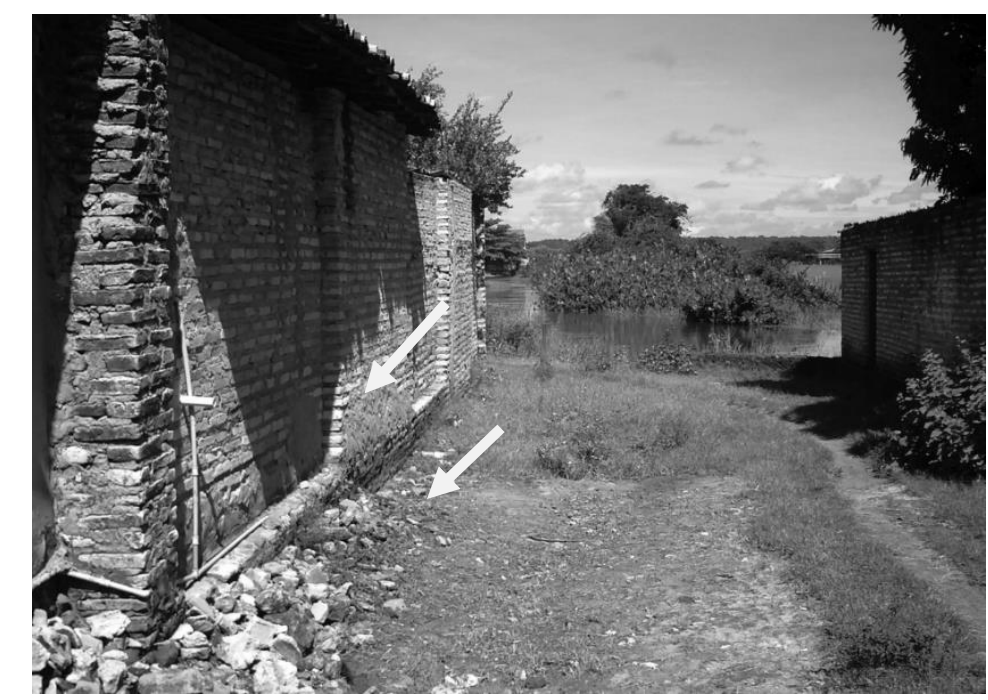

Figura 3 - Lateral de uma casa com o Rio Buriti passando logo ao fundo. Destacaram-se com setas as saídas de águas servidas.

Fonte: Enio Oliveira, 2010. 
Observou-se que, em algumas casas, as fossas têm encanamento direto para o rio, ou seja, a fossa é esvaziada no corpo d'água. Esse fato causa um sério problema de saúde pública, já que muitas pessoas utilizam o rio das mais diversas formas, além dos impactos ambientais envolvidos nessa prática.

Os resíduos sólidos da maioria das casas são coletados pela prefeitura. Em outras casas, parte do lixo é queimado, jogado em terreno baldio ou enterrado. Todas essas situações têm uma possível explicação, já que em uma das ruas onde foram aplicados os questionários não há coleta pública. Entretanto, essa é a rua onde as casas estão mais próximas ao rio, como mostra a Figura 4, ou seja, são casas que podem ser consideradas com grande potencial para poluir o rio. Essa proximidade das casas com o rio e sua relação com a quantidade de lixo encontrada no próprio rio, principalmente no período de chuva, foi observada por Caldas e Rodrigues (2005) no município de Santana do Maranhão/MA.

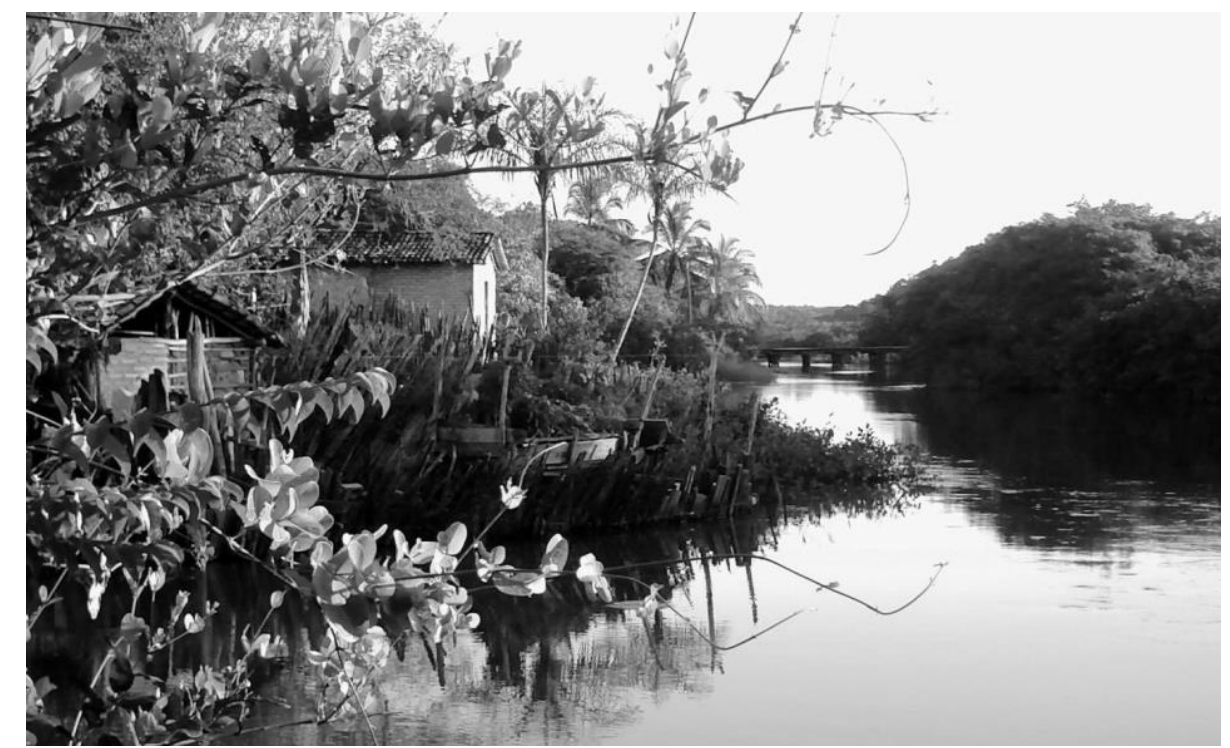

Figura 4 - Fundo das casas em contato direto com a água do Rio Buriti.

Fonte: Enio Oliveira, 2010.

Visando investigar a percepção ambiental dos participantes, algumas questões foram acrescentadas ao questionário. Na primeira delas, em relação ao lixo, perguntouse aos entrevistados o que eles fariam com o lixo, presente em sua mão, se estivessem na rua. Observou-se que 30,2\% afirmaram que jogariam o lixo no chão; $10,9 \%$ jogariam em local de acúmulo de lixo, por exemplo numa calçada; 7,6\% procurariam uma lixeira, mas se não encontrassem jogariam no chão. Somando todos esses percentuais, $48,7 \%$ das pessoas acabariam por dispor o lixo no chão mesmo, o que pode evidenciar a não preocupação ambiental com os resíduos sólidos. Muitas pessoas afirmaram que jogam no chão devido ao fato de não haver lixeiras nas ruas.

Em relação ao Rio Buriti, 90 participantes $(75,6 \%)$ utilizam o rio nas mais diversas formas: para o banho, lavagem de roupas ou louças, para o lazer, para o consumo, para a pesca e outros fins. Essas diversas formas de utilização mostram a importância do rio para a população da cidade, sendo que algumas pessoas relataram espontaneamente que utilizam o rio somente quando falta água, porém a questão de falta de água na cidade é muito frequente, o que foi possível constatar durante a permanência no local para realização da pesquisa. Além disso, uma das ruas onde foram aplicados os questionários é a principal rua da cidade (que recebe diferentes nomes durante seu 
percurso) e possui casas de alto padrão, sugerindo que os moradores possuam uma condição econômica satisfatória, e, mesmo assim, alguns afirmam utilizar o rio.

A forma de utilização mais citada foi o banho, fato que difere dos dados de Martins e Lopes (2009), em que 69\% dos entrevistados afirmaram que não tomam banho no Rio Anil. Vale ressaltar que o grau de poluição do Rio Anil, em relação ao Rio Buriti, deve ser maior, visto que o Rio Anil está localizado em São Luís?MA (com aproximadamente 1 milhão de habitantes). De acordo com os mesmos autores, muitos entrevistados relataram que, quando entravam em contato com a água do rio, ficavam doentes, fato também relatado pelos participantes da pesquisa no Rio Buriti.

Com relação à importância da mata ciliar, 111 entrevistados (93,3\%) consideram-na importante. Esse percentual assemelha-se ao encontrado por Carvalho, Rocha e Missirian (2009) ao avaliar a percepção ambiental de alunos do ensino fundamental de Caarapó/MS, em relação à mata ciliar, em que $91 \%$ dos alunos acham a mata ciliar importante. Os motivos da importância estão apresentados na Figura 5. Alguns entrevistados optaram por mais de uma resposta.

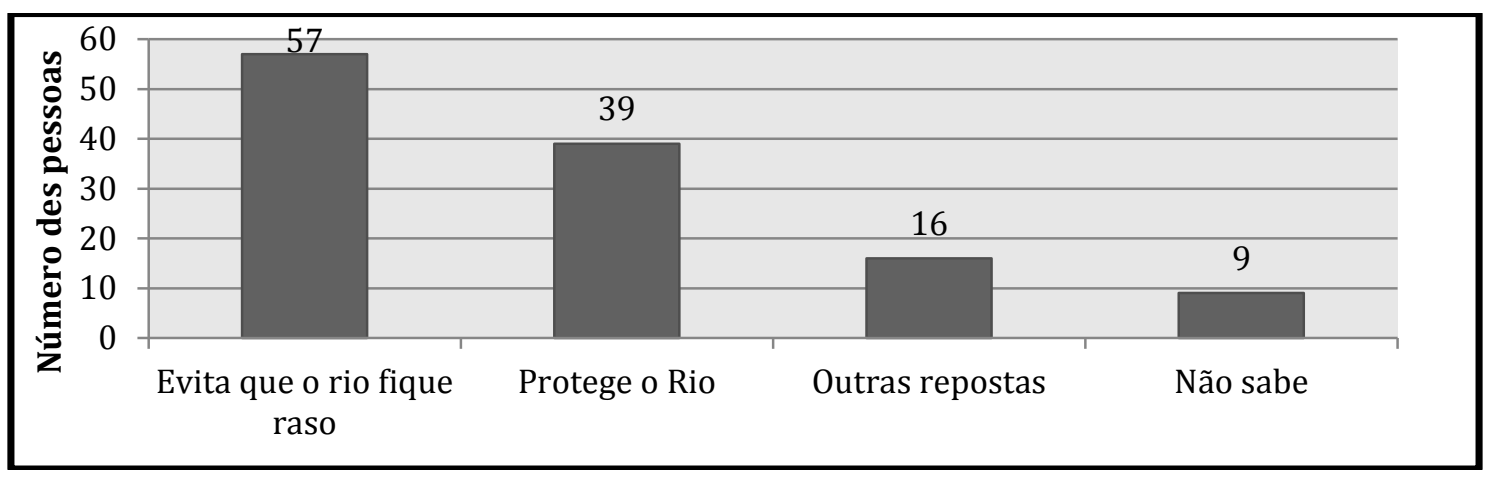

Figura 5 - Opinião dos participantes sobre a importância da mata ciliar

De forma geral, os participantes têm um determinado conhecimento a respeito da importância da mata ciliar para o rio, já que $57(47,1 \%)$ afirmam que a mata evita que o rio fique raso e $39(32,2 \%)$ afirmam que protege o rio. Se considerarmos ambas afirmações como sinônimos, podemos aceitar que esses dados são semelhantes aos encontrados por Carvalho, Rocha e Missirian (2005), em que 74\% atribuíram a importância à função de proteção do riacho.

Meirelles, Silva e Martins (2004), ao analisarem programas de recomposição de mata ciliar em dois municípios do Estado do Paraná, perceberam, através de questionários, a opinião de produtores rurais a respeito da mata ciliar, e afirmam que estes sabem sobre a importância de preservá-la, visando à proteção das nascentes e para evitar a erosão.

Com base nos dados, nota-se que alguns moradores (13\%) possuem um conhecimento limitado ou equivocado acerca dessa importância, já que afirmaram que a importância da mata ciliar está relacionada ao sombreamento, à natureza ou à beleza.

De acordo com Tuan (1980), a forma pela qual se percebe o meio ambiente, suas anomalias, alterações e belezas variam de pessoa para pessoa, de cultura para cultura, e da condição social. Exatamente isso que se identificou nas respostas, as diferentes formas de percepção com relação ao rio e seu entorno. Na análise dos dados, observouse que a percepção dos participantes está relacionada ao grau de escolaridade, uma vez que o percentual de analfabetos, em sua maioria, não relatou causas e consequências coerentes da degradação do rio. 
Em relação ao desmatamento da mata ciliar ou de áreas bem próximas ao rio, 114 pessoas $(95,8 \%)$ disseram que nunca desmataram e somente 5 pessoas $(4,2 \%)$ afirmaram já ter desmatado.

Com o intuito de avaliar mais a fundo a percepção ambiental dos participantes, foi feita a seguinte pergunta no questionário: o que lhe chama mais atenção no rio? $\mathrm{O}$ resultado é apresentado na Figura 6.

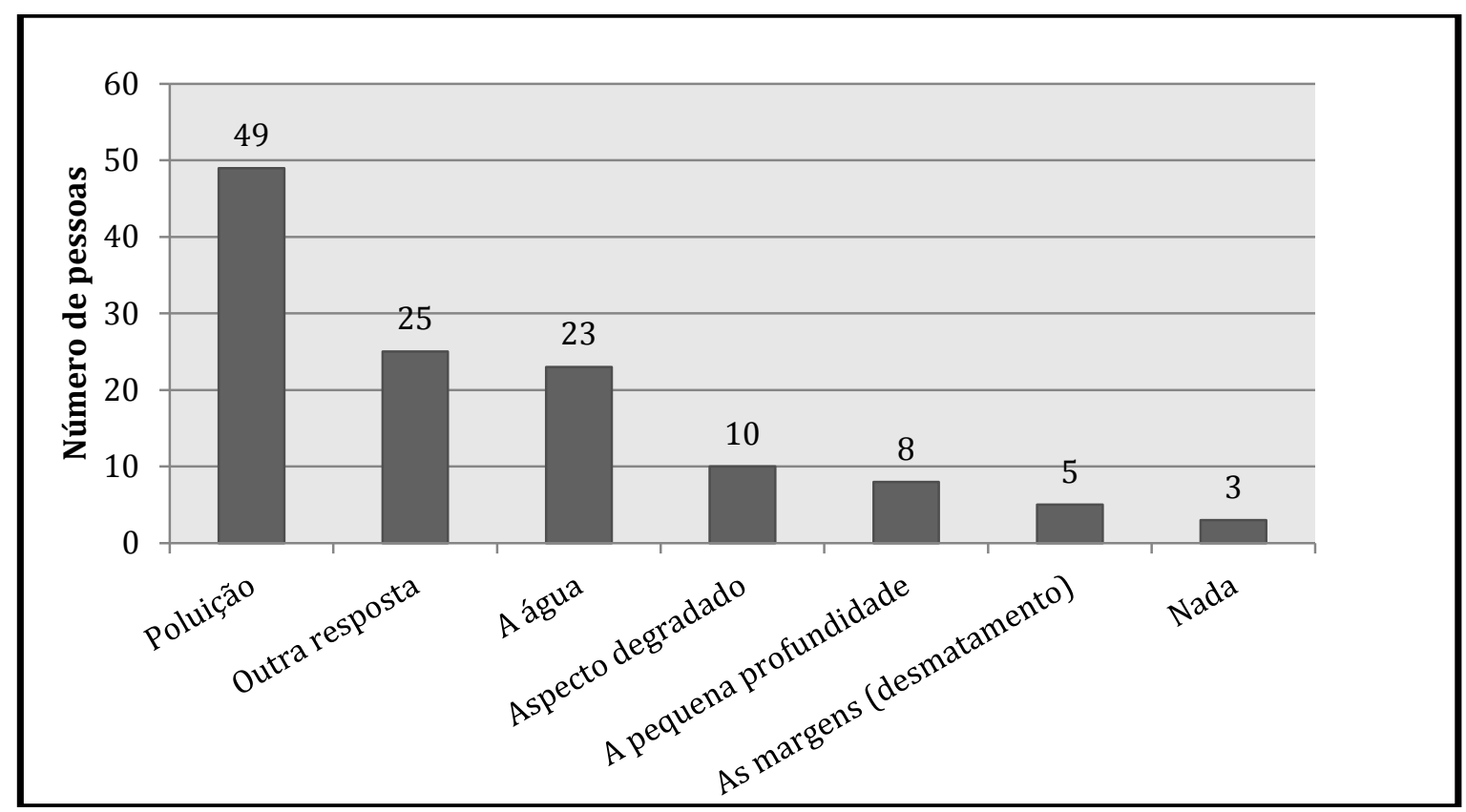

Figura 6 - O que chama mais atenção dos participantes.

Observa-se que, em 49 respostas (ou seja, para 41,2\% das pessoas), a poluição é o que chama mais atenção, sendo que dessas, 25 acrescentaram que é a poluição por lixo, 6 por lixo e esgoto e 2 por esgoto. Esses dados comprovam como a poluição do Rio Buriti já é percebida por boa parte dos participantes. Somando-se as pessoas que destacaram o aspecto degradado (10), as que apontaram o desmatamento das margens (5), e as que se referiram à pequena profundidade (8) ao número de pessoas que destacaram a poluição, tem-se um total de 72 participantes, ou seja, 58,5\% perceberam os impactos ambientais que o rio vem sofrendo. Dados de Martins e Lopes (2009) mostram a questão do lixo como o problema ambiental mais percebido. Também dados de Silva et al. (2005) mostram a questão do lixo como fator que causa maior dano ao rio, apresentando um percentual de $67 \%$ de participantes que apontam esse problema.

Em relação à destruição do Rio Buriti, os participantes manifestaram algumas opiniões, como pode ser observado na Figura 7. A maioria dos participantes (67), acredita que se continuarmos com o ritmo de degradação observado atualmente o rio vai desaparecer. Além desses, 17 pessoas escolheram a mesma opção em conjunto com outra(s), (ou seja, respondendo mais de uma opção), totalizando, dessa forma, 84 participantes, o equivalente a um percentual de 70,5\%. Fato semelhante ocorreu em trabalho realizado por Silva et al. (2005), que avaliou a percepção ambiental do Rio Itapecuru, em seis municípios do Estado do Maranhão. Nesse trabalho, boa parte dos entrevistados de dois municípios afirmou que o rio morrerá no máximo em duas décadas. Dados de Caldas e Rodrigues (2005) mostram uma posição semelhante dos entrevistados em relação ao futuro do rio em questão. Os autores afirmaram que a maioria estava tendo uma visão unilateral, ou seja, estava colocando a responsabilidade 
em terceiros, no caso as autoridades. Relatos desse tipo também foram ouvidos no decorrer da aplicação dos questionários desta pesquisa, indicando que os moradores associam a responsabilidade pela recuperação do rio ao poder público, furtando-se, de certo modo, à responsabilidade de manter os recursos hídricos em boas condições. Por outro lado, alguns participantes acreditam que se for feita alguma coisa, o rio vai melhorar. Essa afirmação dos populares sugere que os mesmos atribuem a outros a responsabilidade de agir para a melhoria da qualidade ambiental do rio, geralmente, esperando do poder público ações efetivas sobre a situação atual de degradação ambiental. As causas de degradação do rio, apontadas pelos entrevistados, são apresentadas na Figura 8.

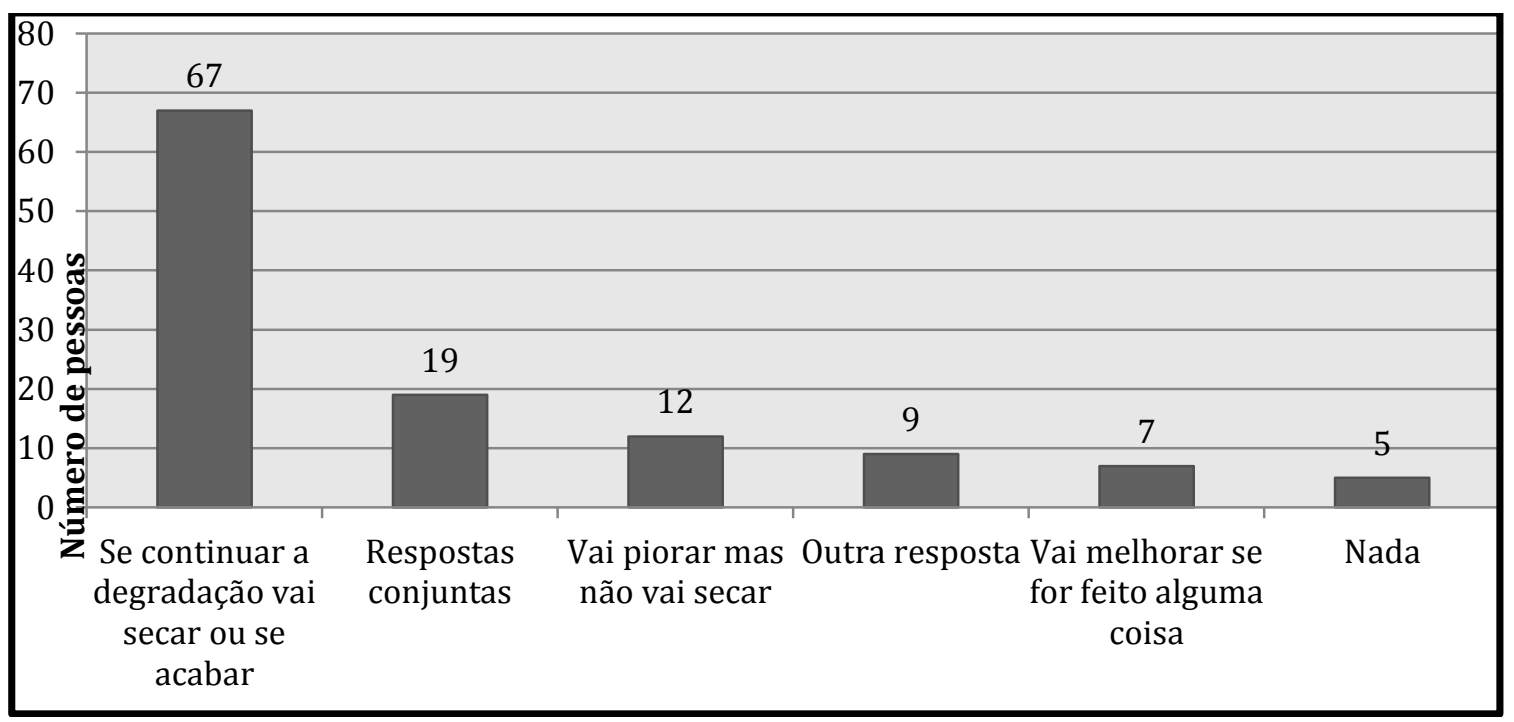

Figura 7 - Opinião dos participantes sobre o futuro do Rio Buriti

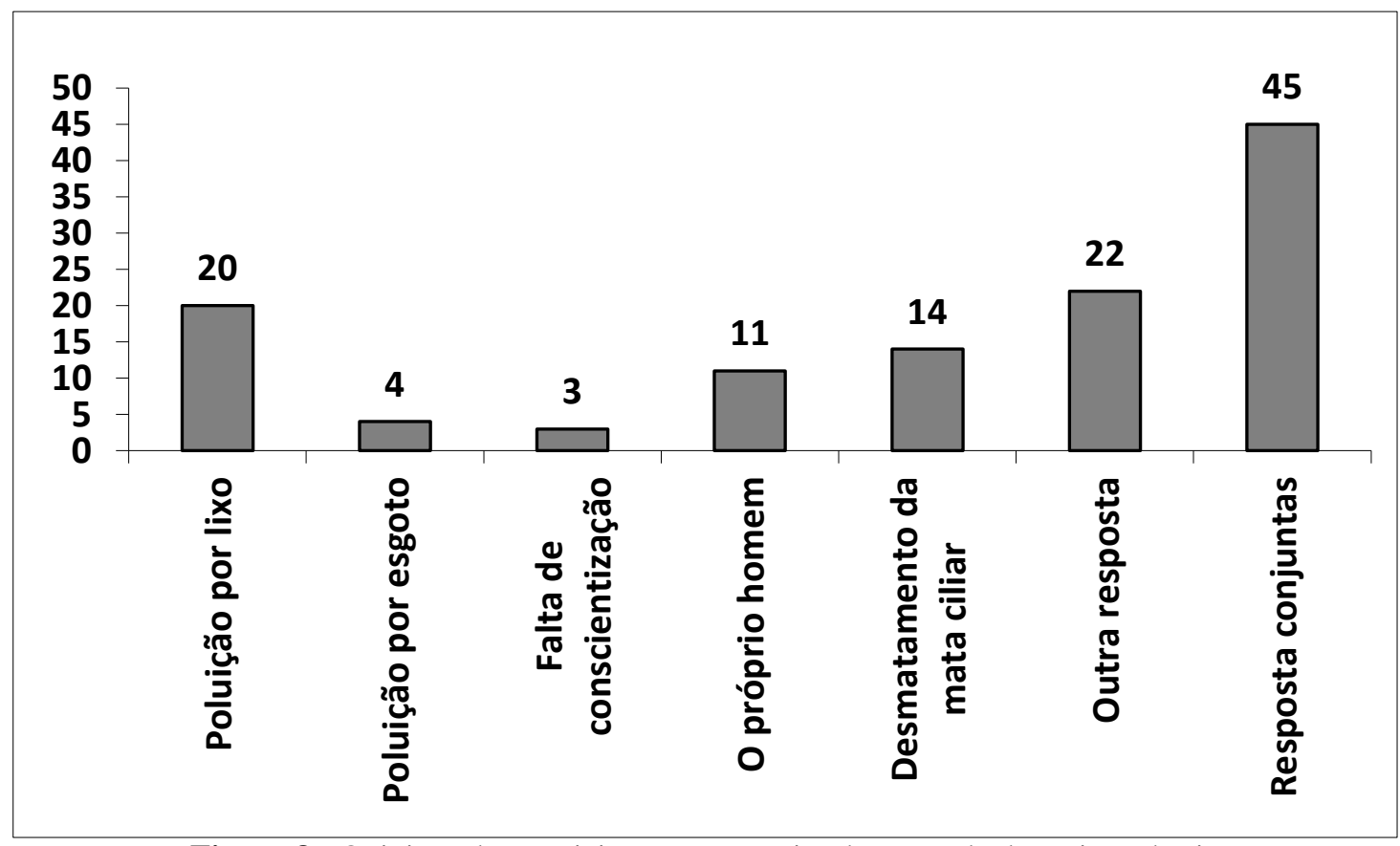

Figura 8 - Opiniões dos participantes a respeito da causa da destruição do rio 
Ao analisar a Figura 8, um dado que chama atenção é o número de pessoas (45) que responderam que a destruição do rio possui mais de uma causa. Isto denota uma boa percepção dos impactos ambientais que ocorrem sobre o rio. Dessas pessoas, 26 citaram a poluição por lixo, 24 o desmatamento da mata ciliar, 14 a poluição por esgoto e 10 outras respostas indicam a retirada de areia como uma das causas da destruição do rio. Somando-se essas respostas, a poluição por lixo foi a mais citada causa da degradação, seguida do desmatamento da mata ciliar e da poluição por esgoto. Nos dados de Caldas e Rodrigues (2005), foram apontados como atividades que causam maior impacto na Bacia do Rio Magu: o descarte de lixo a céu aberto e o desmatamento da mata ciliar, ambos com mais de $80 \%$ de citações. Esses fatos são indicadores de temas que podem ser abordados em programas de Educação Ambiental com o objetivo de mudar essa realidade do município. Porém, considerando-se a afirmação de Tozoni-Reis (2006), os temas mais comumente tratados nas propostas educativas ambientais como recursos hídricos, resíduos sólidos, desmatamento, queimadas, mata ciliar, extinção das espécies animais etc., só têm perspectiva educativa plena se abandonarmos o caráter conteudista da pedagogia tradicional - que trata os conteúdos como objetivos em si mesmos - e dermos um tratamento problematizador a eles, isto é, se, a partir do processamento das informações sobre tais temas, educadores e educandos buscarem empreender reflexões acerca dos conflitos que emergem dos condicionantes históricos, políticos, sociais e culturais dos problemas e soluções ambientais.

Os resíduos sólidos trazem vários impactos ambientais negativos. Segundo Mucelin e Bellini (2008), esses impactos podem provocar a contaminação de corpos d'água, assoreamento, enchentes e proliferação de vetores transmissores de doenças.

Com relação ao desmatamento das matas ciliares, são muitas as consequências, consideradas como principais a perda da biodiversidade e da proteção ao corpo d'água. De acordo com Barrela et al. (2001), essas matas são fundamentais ao equilíbrio ecológico, pois protegem os recursos hídricos e o solo ao diminuir o assoreamento de rios, lagos e represas, atuando como filtro que impede que o meio aquático seja poluído por agentes trazidos por águas que passam pela bacia de drenagem. Além disso, Lima e Zakia (2001) destacam que essas matas ocupam as áreas mais dinâmicas da paisagem, tanto em termos hidrológicos, como ecológicos e geomorfológicos, fato que podemos compreender melhor se percebermos que a mata ciliar percorre grandes extensões de terra ao longo das margens dos rios, ligando fragmentos de vegetação e funcionando como um corredor ecológico, permitindo a troca gênica e outros fenômenos ligados à conservação da biodiversidade. Segundo Krupek e Felski (2006), a destruição da mata ciliar altera o índice de luminosidade incidente, a composição química e a temperatura da água, interferindo diretamente sobre as espécies.

A poluição por esgoto também traz várias consequências. Segundo Martinelli et al. (2002), um dos maiores problemas ambientais do Brasil é a grande carga de esgoto lançada aos corpos hídricos sem um prévio tratamento. $\mathrm{O}$ aporte de matéria orgânica e nutrientes, propiciado pelos esgotos, modifica o funcionamento dos sistemas aquáticos, interferindo na flora e na fauna locais (DAUBA et al., 1997; NOPPE et al., 1999; GONI-URRIZA et al., 1999; NADEN; COOPER, 1999; KONING; ROSS, 1999). Isso acontece em decorrência do processo de eutrofização que, conforme Ferreira (2001), é o processo em que as águas de um sistema sofrem um enriquecimento de nutrientes e suas manifestações relacionadas, tais como alterações no fitoplâncton, alterações no teor de oxigênio dissolvido, interferindo na cadeia alimentar, no aporte nutricional e energético. Com isso a qualidade da água diminui, os peixes desaparecem e o recurso hídrico fica 
limitado ou inexistente. Dessa forma, a comunidade que utiliza tais recursos fica prejudicada.

Com o intuito de identificar as soluções propostas pela comunidade em relação à questão ambiental local, perguntou-se o que deveria ser feito para melhorar o aspecto atual do rio (Figura 9).

Considerável parte dos participantes $(35,2 \%)$ acredita que a conscientização da população é o melhor caminho para mudar a situação atual do Rio Buriti. No entanto, esses dados apresentaram maior diversidade de respostas (31,9\%), dentre as quais destacam-se as seguintes sugestões: fiscalizar, impedir o desmatamento e a retirada de areia, conscientizar a população, saneamento básico, melhorar a infraestrutura de estabelecimentos comerciais, conservar a mata ciliar, colocar lixeiras nas ruas, preservar, fazer campanhas, criar ONGs, Educação Ambiental para crianças, entre outras. 5\% dos entrevistados considera que despoluir o rio seria a melhor solução, $4 \%$ sugerem a recuperação da mata ciliar, 2,5\% que fazem-se necessárias ações por parte da prefeitura, um morador $(0,8 \%)$ entende que a comunidade deve se mobilizar e um morador $(0,8 \%)$ pensa não haver solução.

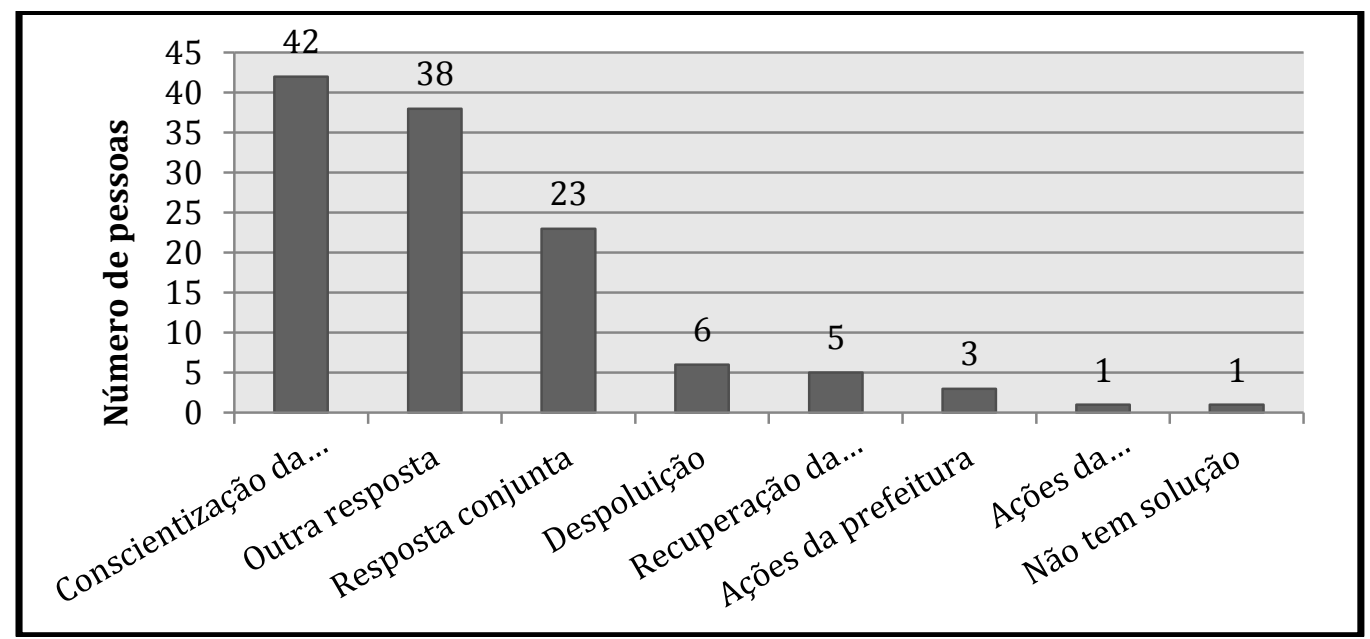

Figura 9 - Soluções apresentadas pelos participantes da pesquisa para melhorar $\mathrm{o}$ aspecto atual do rio

\section{Considerações Finais}

A população estudada é composta, na sua maioria, pelo gênero feminino, o que pode ser justificado pelo fato de a pesquisa ter sido realizada pela manhã, uma vez que neste horário os homens daquela comunidade estão fora de casa, trabalhando. Um terço possui ensino fundamental incompleto e a maior parte está na faixa etária entre 16 e 30 anos, identificando uma realidade preocupante: uma defasagem no grau de escolaridade dos moradores, fato este que pode servir como referência para trabalhos futuros na área educacional.

$\mathrm{Na}$ investigação da percepção ambiental dos participantes, constatou-se que $48,7 \%$ declararam jogar o lixo no chão; a grande maioria dos participantes $(75,6 \%)$ utiliza o Rio Buriti das mais diversas formas, desde banho, lavagem de roupas ou louças, pesca, lazer e consumo, demonstrando a sua importância para a comunidade; 93,3\% dos participantes consideram a mata ciliar importante, com destaque para as funções de evitar o assoreamento do rio, como uma das ações de proteção; mais de $90 \%$ 
dos participantes afirmaram nunca ter desmatado a mata ciliar, embora ela esteja bastante impactada; a degradação do rio chamou a atenção da maioria dos participantes, através da poluição e do desmatamento das margens; 37,8\% dos participantes identificaram mais de uma causa de destruição do rio, sendo a poluição causada pelo lixo a de maior destaque; $35,2 \%$ dos participantes afirmaram que a conscientização é uma das soluções para a problemática do Rio Buriti; 70,5\% dos participantes acreditam que se continuar a degradação o rio vai secar.

Esse conjunto de dados é um importante referencial para futuros trabalhos de Educação Ambiental envolvendo essa comunidade, já que apresenta informações essenciais, como as causas da destruição do rio mais apontadas pelos participantes, que passam a ser interessantes temas educacionais.

Pode-se observar que a questão de saneamento básico na cidade é precária e preocupante, principalmente no que diz respeito aos efluentes domésticos, que acabam tendo como destino o rio. Além disso, a cidade não possui lixeiras nas ruas, sendo boa parte do lixo produzido carreada para dentro do rio, principalmente na época das chuvas.

Trabalhos de Educação Ambiental devem ser implantados na cidade, visando modificar essa realidade local, buscando sempre a minimização dos impactos ambientais e a conscientização das pessoas.

\section{Referências}

BARRELA, W. et al. As relações entre matas ciliares, os rios e os peixes. In: RODRIGUES, R.R. et al. Matas ciliares: conservação e recuperação. 2 ed. São Paulo: USP/FAPESP, 2001. p. 187-207.

BERGMANN, M. Análise da percepção ambiental da população ribeirinha do Rio Santo Cristo e de estudantes e professores de duas escolas públicas, município de Giruá, RS. 2007. 103f. Dissertação (Mestrado em Ecologia) - Universidade Federal do Rio Grande do Sul. Porto Alegre, 2007. Disponível em:

<https://www.lume.ufrgs.br/bitstream/handle/10183/10950/000600097.pdf?sequence=>. Acesso em: 13 dez. 2014.

CALDAS, A. L. R.; RODRIGUES, M. S. do. Avaliação da percepção ambiental: estudo de caso da comunidade ribeirinha da microbacia do Rio Magu. Rev. eletrônica Mestr. Educ. Ambient., Rio Grande, v.15, s/n, p.181-195, Jul./Dez. 2005. Disponível em:

<http://www.seer.furg.br/remea/article/view/2934/1659>. Acesso em: 13 dez. 2014.

CARVALHO, E. M. de; ROCHA, V. S.; MISSIRIAN, G. L. B.; Percepção Ambiental e sensibilização de alunos do ensino Fundamental para preservação da mata ciliar. Rev. eletrônica Mestr. Educ. Ambient. Rio Grande, v. 23, s/n, p.68-82, Jul./Dez. 2009. Disponível em: <http://www.seer.furg.br/remea/article/view/3962/2358>. Acesso em: 13 dez. 2014.

DAUBA F.; LEK S.; MASTRORILLO S.; COPP, G.H. Long-term recovery of macrobenthos and fish assemblages after water pollution abatement measures in the River Petite Baise (France). Archives of Environmental Contamination and Toxicology, New York, v. 33, n.3, p.277-285, 1997. Disponível em:

<http://link.springer.com/article/10.1007/s002449900254\#page-1>. Acesso em: 13 dez. 2014. 
FAGGIONATO, S. Percepção ambiental. In: Programa Educ@r. Portal do Programa de Divulgação Científica e Cultural - Projeto de Educação Ambiental. Disponível em: <http://educar.sc.usp.br/biologia/textos/m_a_txt4.html >. Acesso em: 18 nov. 2014.

FERREIRA, S. M. de F. Impacto da eutrofização em Cyathuracarinata(Isopoda), no estuário do Mondego. 2001. 144f. Dissertação (Mestrado em Ecologia) - Universidade de Coimbra. Coimbra, 2001. Disponível em: <https://eg.sib.uc.pt/bitstream/10316/13445/1/Impacto\%20da\%20eutrofiza\%C3\%A7\%C3\%A3o $\% 20$ em\%20Cyathura\%20carinata.pdf>. Acesso em 12 dez. 2014.

GONI-URRIZA, M.; CAPDEPUY, M.; RAYMOND, N.,QUENTIN, C.; CAUMETTE, P. Impact of an urban effluent on the bacterial community structure in the Arga River (Spain), with special reference to culturable Gram-negative rods. Canadian Journal of Microbiology, Otawa, v.45, n.10, p.826-832, 1999.

INSTITUTO BRASILEIRO DE GEOGRAFIA E ESTATÍSTICA - IBGE.IBGE Cidades@. Disponível em: <http://www.cidades.ibge.gov.br/xtras/perfil.php?lang=\&codmun=211060\&search=maranhao|s ao-bernardo>. Acesso em: 12 dez. 2014.

KONING, N.; ROOS, J.C. The continued influence of organic pollution on the water quality of the turbid Modder River. Water SA, Pretória, v.25, n.3, p.285-292, 1999.

KRUPEK, R A.; FELSKI, G.: Avaliação da Cobertura Ripária de Rios e Riachos da Bacia Hidrográfica do Rio das Pedras, Região Centro-Sul do Estado do Paraná. Revista Ciências Exatas e Naturais, Guarapuava, v. 8 n.2, p.179-188, Jul./Dez. 2006. Disponível em: <http://revistas.unicentro.br/index.php/RECEN/article/viewFile/179/234>. Acesso em $12 \mathrm{dez}$. 2014.

LIMA, R. T. de. Percepção ambiental e participação pública na gestão dos recursos hídricos: perfil dos moradores da cidade de São Carlos, SP (Bacia hidrográfica do Rio do Monjolinho). 2003. 114f. Dissertação (Mestrado em Ciências da Engenharia Ambiental) - Universidade de São Paulo/ Escola de Engenharia de São Carlos. São Carlos, 2003.

LIMA, W. de P.; ZAKIA, M.J.B. Hidrologia de matas ciliares. In: RODRIGUES, R. R. et al. Matas ciliares: conservação e recuperação. 2 ed. São Paulo: Editora da Universidade de São Paulo/FAPESP, 2001. p.33-43.

MARQUES, L. M.; CARNIELLO, M. A.; NETO, G. G. A percepção ambiental como papel fundamental na realização de pesquisa em educação ambiental. Revista Travessias, Cascavel, v.4, n.3, p. 337-349, Dez. 2010. Disponível em:

< http://e-revista.unioeste.br/index.php/travessias/article/view/4616 >. Acesso em: 13 dez. 2014.

MARTINELLI, L. A.; SILVA, A. M. da; CAMARGO, P. B. de; MORETTI, L. R.; TOMAZELLI, A. C.; SILVA, D. M. L. da; FISCHER, E. G.; SONODA, K. C.; SALOMÃO, M. S. M. B. Levantamento das cargas orgânicas lançadas nos rios do estado de São Paulo. Biota Neotropica, Campinas, v.2, n.2, p.1-18, Ago. 2002. - Disponível em: <

http://www.biotaneotropica.org.br/v2n2/pt/fullpaper?bn01502022002+pt>. Acesso em: $13 \mathrm{dez}$. 2014.

MARTINS, A. L. P.; LOPES, M. J. S. Caracterização da população ribeirinha do estuário do Rio Anil (São Luís - MA), com base em aspectos sociais, econômicos e ambientais. Boletim do Laboratório de Hidrobiologia, São Luís, v.22, n.1, p.9-16, 2009. 
MEIRELLES, E. M. T. M.; SILVA, O. H. da; MARTINS, S. S. Análise comparativa de um programa de recomposição da mata ciliar em dois municípios do Noroeste do Estado do Paraná. Acta Scientiarum. Agronomy, Maringá, v. 26, n.2, p.219-226, 2004.

MUCELIN, C. A.; BELLINI, M. Lixo e impactos ambientais perceptíveis no ecossistema urbano. Sociedade\&Natureza, Uberlândia, v.20 n.1, p.111-124, Jun. 2008. Disponível em: <http://www.scielo.br/pdf/sn/v20n1/a08v20n1>. Acesso em: 13 dez. 2014.

NADEN, P.S.; COOPER, D.M. Development of a sediment delivery model for application in large river basins. Hydrologycal Process, Chichester, v.13, n.7, p.1011-1034, May. 1999.

NOPPE, K.; PRYGIEL, J.; COSTE, M.; LEPRÊTRE, A. Phytoplankton of the canalized scarpe river downstream from the Douai sewage treatment plant. Journal of Freshwater Ecology, Oxford/New York, v.14, n.2, p. 167-177, Apr. 1999.

OKAMOTO, J. Percepção ambiental e comportamento. São Paulo: Makenzie, 2003.

SILVA, R. M. N. da; GOMES, L. V.; FREITAS, M. I. da C.; GEDEON, A. D.; DUARTE, M. do C. Percepção ambiental do rio Itapecuru, nas cidades de Pirapemas, Cantanhêde, Itapecuru Mirim, Bacabeira, Santa Rita e Rosário. CONGRESSO BRASILEIRO DE ENGENHARIA SANITÁRIA E AMBIENTAL, 23, Campo Grande, 2005. Anais... Campo Grande: Assoc. Bras. de Eng. Sanit. E Amb., 2005. p.1-9. Disponível em: <http://www.bvsde.paho.org/bvsacd/abes23/VI-007.pdf>. Acesso em: 13 dez. 2014.

TOZONI-REIS, M. F. de C. Temas ambientais como "temas geradores": contribuições para uma metodologia educativa ambiental crítica, transformadora e emancipatória. Educar, Curitiba, s/v, n. 27, p.93-110, 2006. Disponível em: <http://www.scielo.br/pdf/er/n27/a07n27.pdf>. Acesso em: 14 dez. 2014.

TUAN, Yi-Fu. Topofilia: um estudo da percepção, atitudes e valores do meio ambiente. São Paulo: Difel, 1980. 